\title{
Pseudo Intestinal Obstruction Treated by Acupuncture - A Case Report
}

\author{
Sharbunisha Wahaab ${ }^{1 *}$, Helen Suban Mohammed Gouse ${ }^{2}$, Suban Mohammed Gouse Saleem ${ }^{3}$ \\ 'Acupuncturist, Cloud Nine Hijama Acupuncture Center, Palavakkam - 600041, Chennai, Tamil Nadu, India; \\ snmksaleem@gmail.com, \\ ${ }^{2}$ Department of Anatomy, Community Coordinator of Medicine Program, Ibn Sina National College for \\ Medical Studies (ISNC), Jeddah - 22421, K.S.A., Saudi Arabia; dr_helenghouse@yahoo.co.in \\ ${ }^{3}$ Department of Microbiology and Pathology, Ibn Sina National College for Medical Studies, Jeddah - 22421, \\ K.S.A., Saudi Arabia; dr.subanmd@gmail.com
}

\begin{abstract}
Intestinal obstruction is a mechanical or functional obstruction of the intestines which prevents the normal movement of the products of digestion ${ }^{1}$. Either the small bowel or large bowel may be affected ${ }^{2}$. Traditional Chinese Medicine like Acupuncture has been improving human health for a long time. We report a case of Pseudo Intestinal Obstruction of a 38 years old female who received acupuncture treatment as an alternative to Laproscopic Surgery. She was relieved of the symptoms of abdominal pain, nausea, vomiting and high blood pressure. The acupoints used are mentioned and should be considered in a case of imbalance in sympathetic and parasympathetic system. Application of acupoints helps to stimulate the vagus nerve (parasympathetic) and relieves the overstimulation of sympathetic system.
\end{abstract}

Keywords: Acupoints, Acupuncture, Gastro-intestinal Disorder, Pseudo Intestinal Obstruction, Sympathetic overstimulation

\section{Introduction}

Acute intestinal obstruction occurs when there is a disruption in the forward flow of intestinal contents. This obstruction can occur at any point along the length of the gastrointestinal tract, and varied clinical symptoms are noticed based on the level of obstruction. Most commonly intestinal obstruction can be caused by intra-abdominal adhesions, malignancy, or intestinal herniation. The clinical scenario includes nausea and emesis, colicky abdominal pain, and a failure to pass flatus or bowel movements. The classic physical examination findings of abdominal distension, tympany to percussion, and high-pitched bowel sounds suggest the diagnosis. Radiologic imaging can confirm the diagnosis, involving Ultra sonogram and Computed Tomography studies.
Management of uncomplicated obstructions includes fluid resuscitation with correction of metabolic derangements, intestinal decompression, and bowel rest. Evidence of vascular compromise or perforation, or failure to resolve with adequate bowel decompression is an indication for surgical intervention ${ }^{3}$.

Acupuncture is a traditional Chinese medicine treatment and has been practiced empirically in China for around 4000 years. Acupuncture is accomplished by inserting the tips of thin, stainless steel needles on specific points (called acupoints) through the skin. Conventional acupuncture or called "manual acupuncture" involves the manipulation of the inserted needles by hand, such as lifting, thrusting, twisting, twirling or other complex combination. It has been confirmed that acupuncture or Electro Acupuncture

${ }^{*}$ Author for correspondence 
(EA) has therapeutic effects for postoperative dental pain, postoperative and chemotherapy-induced nausea and vomiting ${ }^{4}$. During the last decade, a considerable number of studies have investigated the efficacy of EA for the treatment of functional gastrointestinal disorders. Human and animal studies were conducted to explore the effects of EA on gastrointestinal secretion, sensation, motility and myoelectrical activity ${ }^{5}$.

\section{Case Presentation}

A 38 years old woman complained of severe lower abdominal pain with vomiting for one day. She complained of stress at her work place for the past three days and did not have past episodes of abdominal pain and vomiting. After investigation with Xray, ultrasound and Computed Tomography (CT scan), the findings lead to diagnosis of Sub-acute Intestinal Obstruction (Figure 1-3).

There was past history of Caesarean Section so mechanical obstruction due to adhesions from the previous surgical scar could be a possible cause for obstruction. Obstruction was noticed in the small intestine in Ultrasound scan i.e. lower part of ileum with dilatation of proximal loops of jejunum and $3^{\text {rd }}$ and $4^{\text {th }}$ part of Duodenum, there was no obstruction in large intestine. In follow up contrast CT scan after two days, another radiologist further diagnosed as Pseudo - Obstruction

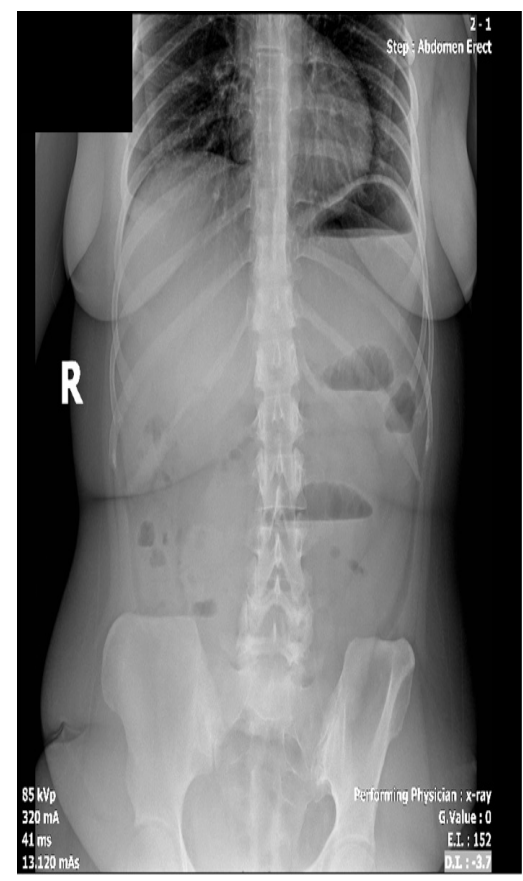

Figure 1. Xray PA view shows air fluid levels.

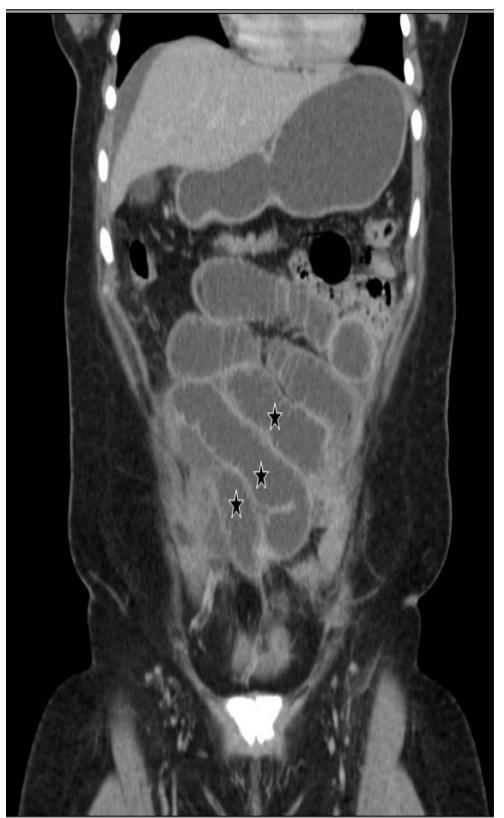

Figure 2. CT scan coronal section shows dilated bowel loops (black stars).

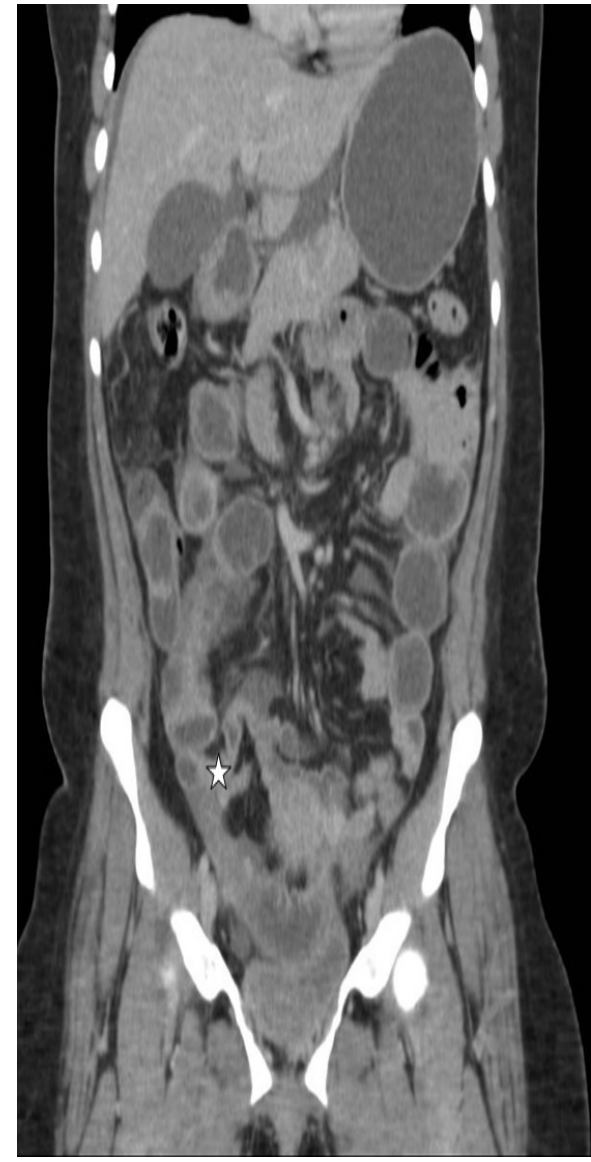

Figure 3. CT scan coronal section shows site of intestinal obstruction (white Star). 
with no evidence of adhesion or bands around the constricted loop and no inner mucosal changes like polyps, Ulcerative Colitis and Crohn's Disease.

The case was managed with two days of conservative management i.e. Nil Per Oral (NPO) with Ryles tube insertion and enema given for intestinal decompression and bowel rest (Figure 4).

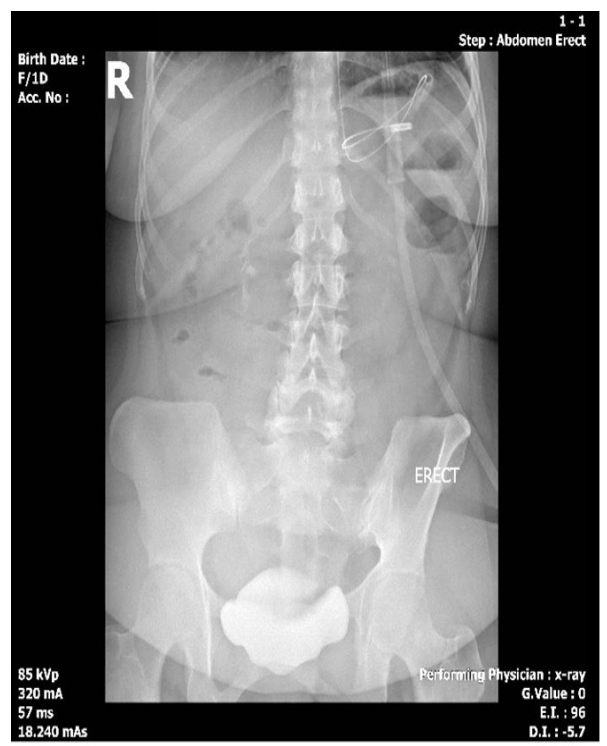

Figure 4. Xray PA view shows no air fluid levels after intestinal decompressed with insertion of Ryle's tube.
After that, she was given oral fluids then semisolids which she couldn't tolerate and started vomiting 2-3 episodes per day. The vomitus was bilious (green coloured) with few food particles. She also passed flatus and stools but still the vomiting had not reduced. She was also severely hypertensive with her BP ranging from 200/130-140/100mm of Hg. She lost 5 kilograms weight within one week and had no appetite.

After eight days of conservative management, the team of doctors suggested for repeat contrast CT to confirm the persistence of obstruction and proceed for explorative Laparoscopy to identify the reason for the obstruction.

However one of the gastroenterologists referred to Acupuncturist, the patient was given NuxVomica Homeopathic medicine (one dose) and then acupunctures two sittings on two consecutive days.

The two sessions of treatment focused on using the acupoints to stimulate the qi in the upper and lower abdomen and to promote bowel movements. The following acupoints applied are mentioned with their indication in (Table 1).

The patient slept well after the second Acupuncture sitting done next day and found relief from all her symptoms. Her Blood Pressure became normal without any medication, Belching, nausea, Vomiting stopped

Table 1. Acupuncture points with their benefits and details of sittings

\begin{tabular}{|c|c|c|c|c|c|c|c|}
\hline $\begin{array}{l}\text { Sl. } \\
\text { No. }\end{array}$ & $\begin{array}{l}\text { Name of } \\
\text { Acupuncture point }\end{array}$ & Benefit & $\begin{array}{l}\text { Day } 1 \\
12 \text { th } \\
\text { Nov. }\end{array}$ & $\begin{array}{l}\text { Day } 2 \\
\text { 13th } \\
\text { Nov. }\end{array}$ & $\begin{array}{l}\text { Day } 3 \\
15 \text { th } \\
\text { Nov. }\end{array}$ & $\begin{array}{l}\text { Day } 4 \\
16 \text { th } \\
\text { Nov. }\end{array}$ & $\begin{array}{l}\text { Day } 5 \\
17 \text { th } \\
\text { Nov. }\end{array}$ \\
\hline 1. & BAIHUI Du 20 & Stress \& Insomnia & + & + & + & + & + \\
\hline 2. & LI $11-$ & $\begin{array}{l}\text { Tonification point, Immunity point, Homeostatic point- } \\
\text { Hypertension \& Stress }\end{array}$ & + & + & + & + & + \\
\hline 3. & Zhigou TW 6 & Vomiting \& sudden turmoil disorder & + & + & + & + & + \\
\hline 4. & LI 4 & $\begin{array}{l}\text { Effective Analgesic Point -Hyper-tension, Absence of sweating } \\
\text { \& Dysenteric disorder }\end{array}$ & + & + & + & + & + \\
\hline 5. & Neiguan P6 & Calm the spirit & + & + & + & + & + \\
\hline 6. & $\begin{array}{l}\text { ZHONGWAN Ren } \\
12\end{array}$ & $\begin{array}{l}\text { Nausea, Stomach reflux, vomiting, Abdominal distention, } \\
\text { Anxiety \& over thinking, }\end{array}$ & + & + & + & + & + \\
\hline 7. & ST 21 & $\begin{array}{l}\text { Epigastric pain, Abdominal distension, Vomiting, poor appetite } \\
\& \text { undigested food }\end{array}$ & + & + & + & + & + \\
\hline 8 & Sp 15 & Abdominal Pain of lower Abdomen, diarrhea \& constipation & + & + & + & + & + \\
\hline 9. & Zusanli ST 36 & $\begin{array}{l}\text { The command point for disorders of the abdomen- Tonification } \\
\text { point, Homeostatic point, immunity point- Digestive dis- } \\
\text { orders, Nausea, Vomiting, poor appetite \& hyper-tension }\end{array}$ & + & + & + & + & + \\
\hline 10. & QUQUAN Liv 8 & $\begin{array}{l}\text { Diarrhea containing un-digested food \& extreme pain of the } \\
\text { body }\end{array}$ & + & + & + & + & + \\
\hline
\end{tabular}


completely and she developed good appetite. Next day, she had repeat contrast CT scan in which all bowel was free from obstruction and some dilatation of bowel was noticed (Figure 5\&6). There was delay in emptying time of intestinal contents.

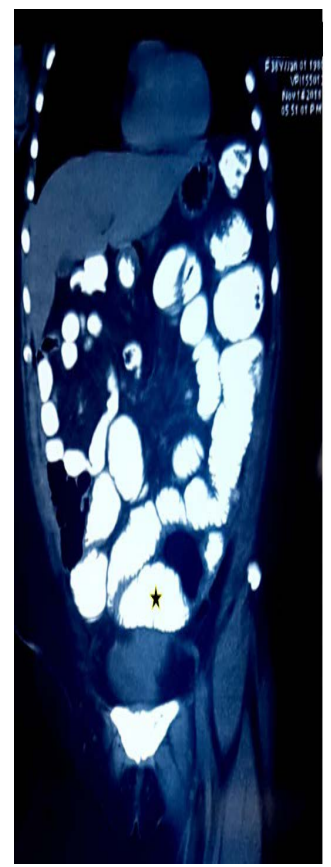

Figure 5. Contrast CT scan coronal view shows filling of dye in the rectum (black star) indicating no obstruction and free flow of bowel contents.

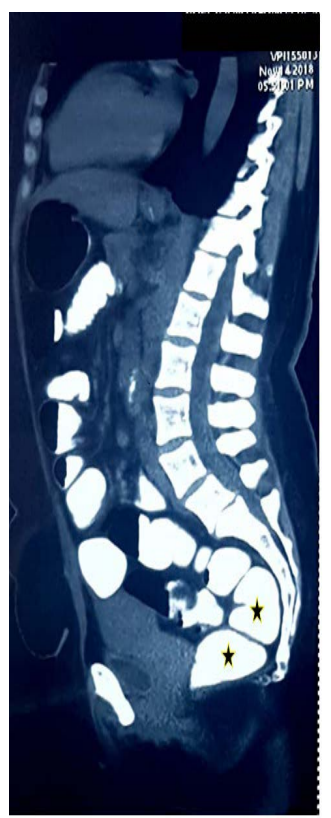

Figure 6. Contrast CT scan Sagittal section shows filling of dye in the rectum (black star) indicating no obstruction and free flow of bowel contents.
The patient continued for another three sittings of Acupuncture settings consecutively after discharge. Following one year of treatment, the patient did not have any recurring symptoms.

\section{Discussion}

It is estimated that between 11 and 43 per cent of patients suffering with gastrointestinal disorders use Complementary Alternative Medicine (CAM) therapies which are beneficial to them ${ }^{6}$. Pseudo Intestinal Obstruction is called as Ogilvie syndrome: acute pseudo -obstruction of the colon in severely ill debilitated patients but in this case, obstruction was seen in the small intestine. This case report suggests that acupuncture may be a treatment option for Pseudo-Intestinal Obstruction (reason for obstruction not known by CT scan) with manifestation of vomiting and severe lower abdominal pain.

The Western diagnosis of Intestinal obstruction relies on the symptoms of abdominal pain and bowel patterns. Traditional Chinese medicine on the other hand emphasizes the importance of a wide spectrum of signs and symptoms presented by the individual patient, and are thus well suited to the treatment of this clinically heterogeneous condition?

Acupuncture at PC6 accelerates bradycardia and decelerates tachycardia, whereas acupuncture at ST 36 suppresses hyperfunction (as in diarrhea) and stimulates hypofunction (as in constipation) of the gut motility ${ }^{8}$. Acupuncture has been believed to improve the vagal tone (beyond deep, slow breathing) ${ }^{9}$. Vagus nerve, the 10th Cranial Nerve which runs from the neck to the abdomen and is parasympathetic control of various organs it is in charge of turning off the "fight or flight reflex" and is suspected to be key to well- being. Stimulating the vagus nerve activates your relaxation response, reduces heart rate and blood pressure ${ }^{10}$.

With regarding to gastric motility functions, it seems that EA enhances gastric accommodation, slow waves, contractions and emptying; suggesting a therapeutic potential for functional dyspepsia and gastroparesis. Little is reported on the effect of EA on small intestinal motility and therefore its role for treating patients with intestinal motility disorders has not been established. Similarly, not much is known on the effect of EA on colon motility and the therapeutic effects of EA for common functional bowel disorders, such as Inflammatory Bowel Disease (IBS), 
constipation and diarrhea, are not conclusive ${ }^{11,12}$. Various theories have been discussed and changing regarding the mechanism of Acupuncture like Meridian-Cortex- Viscera correlation hypothesis (Oldest), acupoint- brain- organ model and morphogenetic singularity theory (latest) ${ }^{11}$.

Herbal or Homeopathic Medicine, which is often used alongside acupuncture for treatment of GI disorders was utilized and found beneficial in this case $\mathrm{e}^{13}$. In conclusion, acupuncture or Electro Acupuncture (EA) is able to alter gastrointestinal motility functions and improve gastrointestinal motility disorders. However, more studies are needed to establish the therapeutic roles of Electro Acupuncture in treating functional gastrointestinal diseases, such as Gastro-Esophageal Reflux Disease (GERD), functional dyspepsia, IBS, constipation and diarrhea ${ }^{7}$.

Given the current limited treatment options for Pseudo Intestinal Obstruction, this case study shows promise of benefit of acupuncture to conventional treatments like surgical options and its complications.

\section{Disclosure Statement}

All authors have contributed to the paper and have never submitted the manuscript, in whole or in part, to other journals.

\section{Acknowledgement}

Prof. Hr. A.W. Salaaudeen, Former Vice-president of ATAMA (All Tamil Nadu Acupuncture and Alternative Medical Association), Founder President of Dr. Wahaab's Pranic healing and Acupuncture for support and guidance during the treatment and in writing this article.

\section{Conflict of Interest}

None.

\section{References}

1. Gore RM, Silvers RI, Thakrar KH, Wenzke DR, Mehta UK, Newmark GM, Berlin JW. Bowel obstruction. Radiologic Clinics. 2015 Nov 1; 53(6):1225-40. https://doi. org/10.1016/j.rcl.2015.06.008. PMid: 26526435.
2. Fitzgerald J, Edward F. Small bowel obstruction. Emergency Surgery. 2010 Feb; 12:74-9. https://doi. org/10.1002/9781444315172.ch14. PMCid: PMC2866215.

3. Jackson P, Raiji MT. Evaluation and Mangement of Intestinal Obstruction. American Family Physician. 2011 Jan 15; 83(2):159-65.

4. Chien TJ, Liu CY, Hsu CH. Integrating acupuncture into cancer care. Journal of Traditional and Complementary Medicine. 2013 Oct 1; 3(4):234-39. https://doi.org/10.4103/22254110.119733. PMid: 24716183, PMCid: PMC3925001.

5. Diehl DL. Acupuncture for gastrointestinal and hepatobiliary disorders. The Journal of Alternative and Complementary Medicine. 1999 Feb 1; 5(1):27-45. https:// doi.org/10.1089/acm.1999.5.27.

6. Spanier JA, Howden CW, Jones MP. A systematic review of alternative therapies in the irritable bowel syndrome. Archives of Internal Medicine. 2003 Feb 10; 163(3):26574. https://doi.org/10.1001/archinte.163.3.265. PMid: 12578506.

7. Anastasi JK, Capili B. The treatment of constipation-predominant irritable bowel syndrome with acupuncture and moxibustion: A case report. The Journal of Chinese Medicine. 2012 Jun; 99:68.

8. Li Y, Tougas G, Chiverton SG, Hunt RH. The effect of acupuncture on gastrointestinal function and disorders. American Journal of Gastroenterology. 1992 Oct 1; 87(10).

9. da Silva MA, Dorsher PT. Neuroanatomic and clinical correspondences: acupuncture and vagus nerve stimulation. The Journal of Alternative and Complementary Medicine. 2014 Apr 1; 20(4):233-40. https://doi.org/10.1089/ acm.2012.1022. PMid: 24359451.

10. Shang C. Mechanism of acupuncture-beyond neurohumoral theory. Med. Acupunct. Online J. 2000; 11(2):61-70.

11. Yin J, Chen JD. Gastrointestinal motility disorders and acupuncture. Autonomic Neuroscience. 2010 Oct 28; 157(12):31-37. https://doi.org/10.1016/j.autneu.2010.03.007. PMid: 20363196, PMCid: PMC2906692.

12. Gouse SS, Ganapathy H, Devi B, Rao GB, Parijatham BO. The challenge in diagnosing Crohn's disease in TB endemic region - A case report with review of literature. Bangladesh Journal of Medical Science. 2018 Sep 19; 17(4):688-90. https://doi.org/10.3329/bjms.v17i4.38340.

13. Butehorn L, Gumz P, Randolph L. Use of Homeopathic Nux Vomica in reducing PAWS (Post Acute Withdrawal Syndrome) in early recovering addicted women. Int. J. Complement Alt. Med. 2017; 6(4):00197. https://doi. org/10.15406/ijcam.2017.06.00197. 